\title{
Synaptic Connections between Layer 5B Pyramidal Neurons in Mouse Somatosensory Cortex Are Independent of Apical Dendrite Bundling
}

\author{
Patrik Krieger, ${ }^{1,2}$ Thomas Kuner, ${ }^{1}$ and Bert Sakmann ${ }^{1}$ \\ ${ }^{1}$ Abteilung Zellphysiologie, Max-Planck-Institut für medizinische Forschung, D-69120 Heidelberg, Germany, and ²Department of Cell and Molecular \\ Biology, Uppsala University, SE-75124 Uppsala, Sweden
}

\begin{abstract}
Rodent somatosensory barrel cortex is organized both physiologically and anatomically in columns with a cross-sectional diameter of $100-400 \mu \mathrm{m}$. The underlying anatomical correlate of physiologically defined, much narrower minicolumns $(20-60 \mu \mathrm{m}$ in diameter $)$ remains unclear. The minicolumn has been proposed to be a fundamental functional unit in the cortex, and one anatomical component of a minicolumn is thought to be a cluster of pyramidal cells in layer 5B (L5B) that contribute their apical dendrite to distinct bundles. In transgenic mice with fluorescently labeled L5B pyramidal cells, which project to the pons and thalamus, we investigated whether the pyramidal cells of a cluster also share functional properties. We found that apical dendrite bundles in the transgenic mice were anatomically similar to apical dendrite bundles previously proposed to be part of minicolumns. We made targeted whole-cell recordings in acute brain slices from pairs of fluorescently labeled L5B pyramidal cells that were located either in the same cluster or in adjacent clusters and subsequently reconstructed their dendritic arbors. Pyramids within the same cluster had larger common dendritic domains compared with pyramids in adjacent clusters but did not receive more correlated synaptic inputs. L5B pyramids within and between clusters have similar connection probabilities and unitary EPSP amplitudes. Furthermore, intrinsically bursting and regular spiking pyramidal cells were both present within the same cluster. In conclusion, intrinsic electrical excitability and the properties of synaptic connections between this subtype of L5B pyramidal cells are independent of the cell clusters defined by bundling of their apical dendrites.
\end{abstract}

Key words: minicolumn; connectivity; dendritic arborization; somatosensory cortex; bundle; cell cluster

\section{Introduction}

The column hypothesis states that the fundamental unit of cortical organization is a group of interconnected neurons that share a certain set of properties and extend vertically through the cortical layers to form a column (Lorente de Nó, 1938; Mountcastle, 1957, 1978, 1997, 2003). Large columns (100-500 $\mu$ m diameter), such as barrel columns in the somatosensory cortex of rodents, are proposed to be formed by interconnected smaller units called "minicolumns" (20-60 $\mu \mathrm{m}$ in diameter) (Hubel and Wiesel, 1974, 1977; Kaas et al., 1981; Favorov and Whitsel, 1988a,b; McCasland and Woolsey, 1988; Favorov and Diamond, 1990; Tommerdahl et al., 1993; Kohn et al., 1997; Bruno et al., 2003; Georgopoulos et al., 2006). Minicolumns would thus be the elementary units that characterize cortex regardless of areal specialization. Critiques of the column hypothesis do not deny the

Received March 16, 2007; revised Aug. 26, 2007; accepted Sept. 3, 2007.

This work was supported by the Max-Planck-Gesellschaft and by a Swedish Research Council fellowship to P.K. We thank Drs. Fritjof Helmchen, Michael Brecht, and Randy Bruno for comments on this manuscript; Fritjof Helmchen for assistance with in vivo two-photon microscopy; Radoslav Enchev for computer programming; Dr. Mayank Mehta for assistance with cross-correlation analysis; Alexander Groh for tracer injections; Marlies Kaiser for expert technical assistance; and Wolfram Schleich for help with breeding and genotyping of mice.

Correspondence should be addressed to Dr. Patrik Krieger, Abteilung Zellphysiologie, Max-Planck-Institut für Medizinische Forschung, D-69120 Heidelberg, Germany. E-mail: patrik.krieger@mpimf-heidelberg.mpg.de. DOI:10.1523/JNEUROSCI.1182-07.2007

Copyright $\odot 2007$ Society for Neuroscience 0270-6474/07/2711473-10\$15.00/0 existence of various forms of neuron clustering; rather, they argue against the idea that a columnar arrangement of cortex is necessary for cortical processing, and instead suggest that columns could be an epiphenomenon of development (Swindale, 1990; Purves et al., 1992; Horton and Adams, 2005). The barrel columns in somatosensory cortex, for example, would not reflect a general cortical organization principle, but rather they would be specific for the sensory modality (Catania, 2002; Horton and Adams, 2005).

The underlying anatomical substrate for a minicolumn has been proposed to be a columnar organization of cells ("pyramidal cell module") with bundled apical dendrites originating from layer 5 pyramidal neurons as the core element (Fleischhauer et al., 1972; Peters and Walsh, 1972; Escobar et al., 1986; Peters and Sethares, 1991, 1996; Peters and Yilmaz, 1993; White and Peters, 1993; DeFelipe, 2005), or vertically aligned rows of cells ("cell columns"), which do not necessarily contain layer 5 pyramidal cells with bundled apical dendrites, that are prominent in primate neocortex (Schlaug et al., 1995; Buxhoeveden et al., 2000). Examples of other repeating anatomical structures that could be components of minicolumns include dendrite bundles formed by layer 6 pyramidal cells, which in mouse neocortex are separate from layer 5 dendrite bundles (Escobar et al., 1986; Lev and White, 1997), and bundles of double bouquet cell axons (DeFelipe et al., 1990). 
Using transgenic mice with fluorescently labeled layer $5 \mathrm{~B}$ (L5B) pyramidal cells having apical dendrites organized in vertically oriented bundles, we were able to target electrical recordings and do physiological measurements from L5B pyramidal cells with their apical dendrite contributing either to the same apical dendrite bundle (cells referred to as in the same cluster) or to adjacent apical dendrite bundles (cells in adjacent clusters). If clustered cells are part of a minicolumn, they should be distinguished from cells in adjacent minicolumns by virtue of a common property. We investigated whether, for example, there is a repeating pattern of intrinsic connectivity that conforms to the repeating pattern of clustered cells. Recordings were made in acute slices of mouse somatosensory cortex with most recordings obtained from barrel cortex.

\section{Materials and Methods}

Transgenic mice (CLM-1 and CLM-11) expressing a chloride-sensitive protein, Clomeleon, were found to label layer 5B pyramidal neurons in neocortex. Approximately $30 \%$ of the total layer $5 \mathrm{~B}$ neuron population was labeled. Clomeleon consists of CFP (cyan fluorescent protein) linked by a short peptide to YFP (yellow fluorescent protein). These mouse lines have been described previously (Kuner and Augustine, 2000; Berglund et al., 2004; Duebel et al., 2006).

Slice preparation. All experimental procedures were in accordance with the German animal welfare guidelines. Coronal slices or thalamocortical slices of barrel cortex were prepared as described previously (Feldmeyer et al., 1999). Briefly, the mouse was decapitated, and the brain was quickly removed. Thalamocortical slices were prepared by placing the brain on a ramp with a $10^{\circ}$ slope, and a vertical cut at an angle of $50^{\circ}$ was made (Agmon and Connors, 1991). The tissue rostral to the cut was discarded, and the brain was glued with the cut surface facing down onto the cooled stage of the tissue slicer. Slices ( $300 \mu \mathrm{m}$ thick) containing the barrel cortex were thus cut tangentially at an angle of $50^{\circ}$ relative to the midsagittal plane. Coronal slices were prepared by placing the anterior part of the brain on a $10^{\circ}$ ramp and then cutting perpendicular to the brain surface, discarding the tissue caudal to the cut. The brain was subsequently glued with the cut surface facing down, and 300- or 400$\mu \mathrm{m}$-thick slices containing the barrel cortex were cut. Slices were maintained at room temperature before recording. All experiments were made close to physiological temperatures $\left(32-34^{\circ} \mathrm{C}\right)$.

Electrophysiology. Patch pipettes for dual whole-cell recordings were filled with (in mM) $105 \mathrm{~K}$-gluconate, $30 \mathrm{KCl}, 10$ phosphocreatine- $\mathrm{Na}_{2}, 10$ HEPES, 4 ATP-Mg, $0.3 \mathrm{GTP}$, with $\mathrm{pH}$ adjusted to 7.3 with $\mathrm{KOH}$ (osmolarity, $300 \mathrm{mOsm}$ ). Biocytin ( $2 \mathrm{mg} / \mathrm{ml}$; Fluka, Neu-Ulm, Germany) was included in the pipette to allow the morphology of the neurons to be reconstructed in the fixed tissue, and a fluorescent dye, Alexa $594(50 \mu \mathrm{M}$; Invitrogen, Eugene, OR) to identify the neurons and to confirm the dendrite branching pattern in the living slice. For cell-attached stimulation, the pipette contained the following solution (in $\mathrm{mm}$ ): $105 \mathrm{Na}$ gluconate, $30 \mathrm{NaCl}, 10 \mathrm{HEPES}, 10$ phosphocreatine, 4 ATP-Mg, and 0.3 GTP (adjusted to pH 7.3 with $\mathrm{NaOH}$ ). The extracellular solution contained the following (in mM): $125 \mathrm{NaCl}, 25 \mathrm{NaHCO}_{3}, 2.5 \mathrm{KCl}, 1.25$ $\mathrm{NaH}_{2} \mathrm{PO} 4,1 \mathrm{MgCl}_{2}, 25$ glucose, and $2 \mathrm{CaCl}_{2}$, continuously bubbled with $95 \% \mathrm{O}_{2}$ and $5 \% \mathrm{CO}_{2}$. The potassium channel blocker 4-aminopyridine (4-AP) was from Sigma-Aldrich (St. Louis, MO).

Data were obtained from 59 Clomeleon mice with an average age of $21 \mathrm{~d}$ (median, $21 \mathrm{~d}$; range, 14-37 d). Clomeleon-labeled L5B pyramidal neurons in distinct cell clusters with vertically projecting apical bundles were chosen for recording. One pipette was used to make whole-cell recordings from one cell in such a cluster, and the second pipette was used to search for connections. The search pipette was used for cellattached stimulation or whole-cell recording. Only cell pairs within 20 $\mu \mathrm{m}$ of one another in the $z$-plane were tested. Cell pairs with no connection in either direction were counted as two unconnected pairs; pairs with a unidirectional connection were counted as one connected pair and one unconnected pair; pairs with a bidirectional connection were counted as two connected pairs. The horizontal distance ( $x$-axis) be- tween neurons was measured from the center of the soma, with the vertical $y$-axis aligned to the apical dendrite.

Recordings were made with an Axoclamp2B amplifier (Molecular Devices, Union City, CA), filtered at $3 \mathrm{kHz}$, and sampled at $10 \mathrm{kHz}$ using custom-written software (Igor; WaveMetrics, Lake Oswego, OR).

Retrograde tracer injection. Mice $(n=2)$ were anesthetized with isoflurane $(1 \%$, mixed with oxygen), and a craniotomy $(3 \times 3 \mathrm{~mm})$ was performed. Subsequently, the mouse head was fixed in a stereotaxis stage. A suspension of fluorescent microspheres (F8794, $0.04 \mu \mathrm{m}$; Invitrogen) was injected into pons or posteromedial thalamic nucleus (POm) by positive pressure to the micropipette. Animals were killed 7-9 d after the injection. Microspheres and Clomeleon-labeled cells were detected in fixed brain slices using confocal microscopy.

Histological procedure. Slices were fixed in $100 \mathrm{~mm}$ PBS containing 4\% paraformaldehyde and kept at $4^{\circ} \mathrm{C}$ for 1-2 d. Cytochrome oxidase histochemistry was used for visualizing barrels. Biocytin-labeled neurons were visualized using a previously published protocol (Lübke et al., 2000; Feldmeyer et al., 2005). The location of the neurons within the barrel cortex could thus be confirmed, and neurons were reconstructed in three dimensions with the Neurolucida software (MicroBrightField, Colchester, VT) using an Olympus (BX 51) or Zeiss (Oberkochen, Germany) microscope with a $100 \times$ objective.

Quantification of anatomical properties. Using custom-written software in MatLab (The Mathworks, Natick, MA), the three-dimensional (3D) reconstructions were used to calculate the dendrite length within $20 \times 20 \times 20 \mu \mathrm{m}$ voxels, which gives the "length density" (micrometers per cubic micrometer) in each voxel. The dendrite overlap is calculated by multiplying the length density, voxel for voxel, from two cells to give the "product density." If a voxel contains dendrite from only one cell, the product is thus zero, and the volume of that voxel is not included. The values for the product density in each voxel were subsequently sorted, and the sum was calculated. Starting from the voxel with the highest product density, voxels were added until the added product densities equaled $80 \%$ of the sum of all product densities. A 3D isosurface plot was subsequently generated that shows the smallest volume that encloses $80 \%$ of the overlapping dendrites. The "percentage dendrite overlap" between two cells was determined as follows. For each cell, the total volume of all voxels containing dendrite was calculated. The "product volume" is the total volume containing dendrites from both cells. This is the total volume of all voxels with a product density more than zero. The dendrite length within a voxel is thus not taken into consideration in the calculation. Percentage dendritic overlap = product volume/[("total volume cell A" + "total volume cell B") - product volume] $\times 100$. The percentage dendritic overlap was calculated separately for each pair (five pairs in the same cluster and six pairs with cells in adjacent clusters).

Sholl analysis using concentric spheres and fractal analysis using the box-counting method was calculated with Neurolucida Explorer (MicroBrightField).

Cross-correlation. Cross-correlation analysis was made with pClamp9 (Molecular Devices). Voltage traces used for cross-correlation were 1-5 min long. Only subthreshold traces were used. The window lag was 200 ms.

Two-photon imaging. Two-photon excitation was made by a Ti:SaLaser (MIRA 900F; Coherent, Santa Clara, CA) set at 820-840 nm and pumped by a solid-state laser (Verdi $5 \mathrm{~W}$; Coherent). Scanning was performed using a resonant scanning unit (TCS-SP2RS; Leica Microsystems, Mannheim, Germany) mounted on an upright microscope (DMLFS; Leica Microsystems) equipped with a $40 \times$ objective (HCX APO; $40 \times$, numerical aperture 0.8; Leica Microsystems). A dichroic mirror (560DCXR) split the fluorescence to one detector (bandpass filter, HQ525/50M) for green fluorescence from Clomeleon-expressing layer 5 pyramidal neurons, and to one detector (bandpass filter, HQ610/75M) recording red fluorescence from Alexa 594. Neurons were visualized with two-photon scanning gradient contrast imaging (Wimmer et al., 2004). On-line superposition of fluorescence and infrared contrast-enhanced image allowed targeted recordings from fluorescently labeled neurons. For in vivo imaging, the mouse $(n=1)$ was anesthetized with urethane (i.p.; $1 \mathrm{~g} / \mathrm{kg}$ of body weight), and a small craniotomy was prepared. The exposed cortex was superfused with warm normal rat ringer (NRR) so- 
A

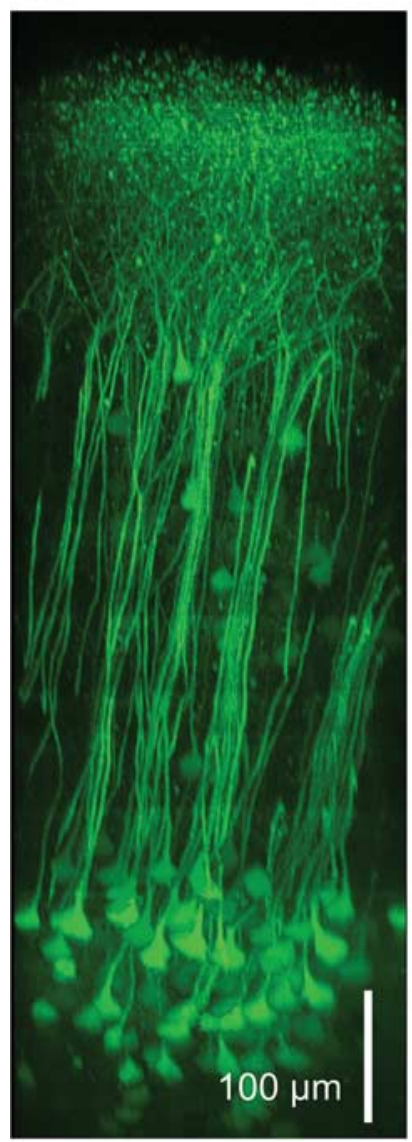

B

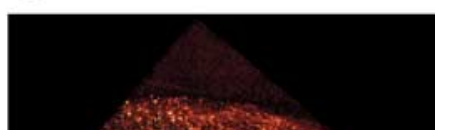

2005). Bundles were clearly visible with two-photon microscopy in vivo (Fig. 1A) (Helmchen and Denk, 2005) and in the acute living brain slice (Fig. $1 B$ ). The fluorescent labeling enabled the visualization of dendrite bundles extending from deep layer 5 to the pial surface. Bundle-forming cells were classified as L5B pyramidal neurons based on their location in the cell-dense lower part of layer 5 (mean distance from pia, $739 \mu \mathrm{m}$ ) and the extensive branching and spread of their apical dendrite tuft (see Figs. 6, 7) (Markram, 1997; Markram et al., 1997; Schubert et al., 2001; Manns et al., 2004). At the level of layer 2/3, the apical dendrites begin to branch into terminal tufts, causing bundles to be less spatially confined. It is also evident that the layer $5 \mathrm{~B}$ pyramidal cell bodies are located vertically below their apical dendrite and that apical dendrites in a given bundle originate from cell somata arranged in clusters (Peters and Walsh, 1972). Each bundle is made up of 5-10 main apical dendrites and their associated somata, with distances of 20-40 $\mu \mathrm{m}$ between the bundle centers. Because the apical dendrite bundle is suggested to form the axes of a minicolumn, the diameter of a minicolumn is defined as the center-to-center distance between dendrite bundles. The clustered L5B pyramidal cells had an ipsilaterally projecting main axon and were retrogradely labeled by injection of fluorescent microspheres into pons and the POm (supplemental Fig. 1, available at www.jneurosci.org as supplemental material). The majority of clustered L5B pyramidal cells are thus corticopontine-projecting neurons with collaterals projecting to thalamus (Deschênes et al., 1994).

In the mouse barrel cortex, bundles were previously described to be located preferentially in the wall of barrels in layer 4, which is defined as the space between barrels (Escobar et al., 1986; White and Peters, 1993). We examined whether bundles have a regular relation to the organization of barrel hollows and walls. From fixed tissue, we prepared tangential sections (50 $\mu \mathrm{m}$ thickness) through layer 4 of barrel cortex. Every second section was stained for cytochrome $c$ to visualize the barrel outlines. After staining, barrels appeared dark and the surrounding wall brighter (Fig. $2 A, B$ ). The average intensity within a region of interest (ROI) in the cytochrome $c$-stained section (Fig. $2 A, B$ ) was compared with the corresponding measurement from the subsequent unstained section with fluorescence from labeled apical dendrites (Fig. 2C). The highest fluorescence in the untreated section was in the brightest areas in the cytochrome $c$-stained section, which corresponds to the barrel walls (Fig. $2 D, E$ ). Thus the apical dendrite bundles at the level of layer 4 are preferentially found in the barrel walls of cytochrome $c$-defined barrels, and consist of a few large-diameter dendrites and several smaller-diameter dendrites (supplemental Fig. 2, available at www.jneurosci.org as supplemental material). The properties we find for apical dendrite bundles in the acute living slice are similar to the properties previously described for apical dendrite bundles in fixed tissue (Escobar et al., 1986; White and Peters, 1993; Lev and White, 1997).

We conclude that a subset of layer 5B pyramidal neurons defined by thy 1 promoter-directed expression of a fluorescent protein are arranged in clusters of 5-10 corticopontine-projecting neurons with apical dendrites forming a bundle.

Comparison of the dendrite branching pattern for cells in the same cluster and in adjacent clusters

To analyze whether L5B pyramidal cells within a cluster have more similarities in their cellular geometry than cells in adjacent clusters, we quantified the 3D arborization of the dendritic trees. In the following section, "cell pair" refers to two cells, in the same
Results
Characterization of bundles formed by apical dendrites of
layer 5B pyramidal neurons
In transgenic mouse lines (CLM-1 and CLM-11) expressing the
chloride-sensitive fluorescent protein Clomeleon, we observed a
pattern of vertically ascending apical dendrites originating from
clustered L5B pyramidal neurons (Fig. 1 A,B). A vertical organi-
zation of apical dendrites organized in bundles has previously
been described in fixed tissue in the somatosensory cortex of mice
(Escobar et al., 1986; White and Peters, 1993) and in other species
and cortical areas (Peters and Walsh, 1972; Peters and Sethares,
1991; Peters and Yilmaz, 1993; Schmolke and Künzle, 1997;
Rockland and Ichinohe, 2004; Buxhoeveden and Casanova,

Results
Characterization of bundles formed by apical dendrites of
layer 5B pyramidal neurons
In transgenic mouse lines (CLM-1 and CLM-11) expressing the
chloride-sensitive fluorescent protein Clomeleon, we observed a
pattern of vertically ascending apical dendrites originating from
clustered L5B pyramidal neurons (Fig. 1 A,B). A vertical organi-
zation of apical dendrites organized in bundles has previously
been described in fixed tissue in the somatosensory cortex of mice
(Escobar et al., 1986; White and Peters, 1993) and in other species
and cortical areas (Peters and Walsh, 1972; Peters and Sethares,
1991; Peters and Yilmaz, 1993; Schmolke and Künzle, 1997;
Rockland and Ichinohe, 2004; Buxhoeveden and Casanova, 
cluster or in adjacent clusters, reconstructed from the same slice. Basal dendrites were compared using the semilog Sholl method, modified for 3D, to calculate the regression coefficient for each cell (Fig. 3A). The number of intersections $(N)$ with increasing radius $(r)$ of concentric spheres, centered on the soma (starting radius $10 \mu \mathrm{m}$ and increasing in steps of 10 $\mu \mathrm{m})$, with volume $V$, was calculated. $\log (N / V)$ was plotted versus sphere radius, and the slope $(k)$ and intercept $(m)$ were calculated with linear regression $[\log (N / V)=k r+m]$. The average Sholl regression coefficient $(k)$ for the basal dendrites was $-0.025 \pm 0.003$ (mean $\pm \mathrm{SD}$; $R^{2}=0.9836 \pm 0.0106 ; n=22$ cells). The Sholl regression coefficient $(k)$ was not significantly different for cell pairs in the same cluster $(p=0.2081$; paired $t$ test; $n=$ 6 ) or for cell pairs in adjacent clusters ( $p=$ 0.7683 ; paired $t$ test; $n=7$ ). This analysis shows that the basal dendrites have similar branching patterns in cell pairs located both in the same cluster and in adjacent clusters. The geometric characteristics of the apical dendrites (including the oblique dendrites) are not well captured by the semilog Sholl method (in part, because of the biphasic distribution of intersections over distance). To compare the apical dendrites, the number of intersections was calculated with Sholl analysis (sphere starting radius, $20 \mu \mathrm{m}$, and increasing in steps of $20 \mu \mathrm{m})$. The cumulative distribution of the number of intersections over distance was calculated and compared for cell pairs in the same and in adjacent clusters (Fig. $3 B$ ). For four of six cell pairs in the same cluster and for six of seven cell pairs in adjacent clusters, the branching pattern was not significantly different $(p>0.05$; Kolmogorov-Smirnov two-sample $t$ test). This result suggests that cells in the same cluster and in adjacent clusters frequently have similar apical dendrite branching patterns (as defined by a nonsignificant difference in the Kolmogorov-Smirnov two-sample $t$ test). To further compare morphological properties, the " $k$-dim" of fractal analysis was calculated, which describes how the structure fills space (Panico and Sterling, 1995). To compare the different dendrite compartments, each reconstructed cell was subdivided into five groups [(1) entire cell (excluding axon), (2) only apical dendrite, (3) only basal dendrites, (4) only oblique dendrites, and (5) only tuft dendrites], and $k$-dim was calculated and compared separately for each group. In each group, the $k$-dim value was similar for cell pairs in the same cluster $(p>0.05$; paired $t$ test) and in adjacent clusters $(p>$ 0.05 ; paired $t$ test). The average $k$-dim values (averaged over all cells; $n=22$ ) for the different groups were (in the same order as above) (1) $1.28 \pm 0.05$, , (2) $1.22 \pm 0.05$, (3) $1.14 \pm 0.04$, (4) $1.13 \pm 0.04$, and (5) $1.17 \pm 0.07$. These anatomical quantifications suggest that morphological similarities are not higher for cells located in the same cluster than for cells located in adjacent clusters.
B

C
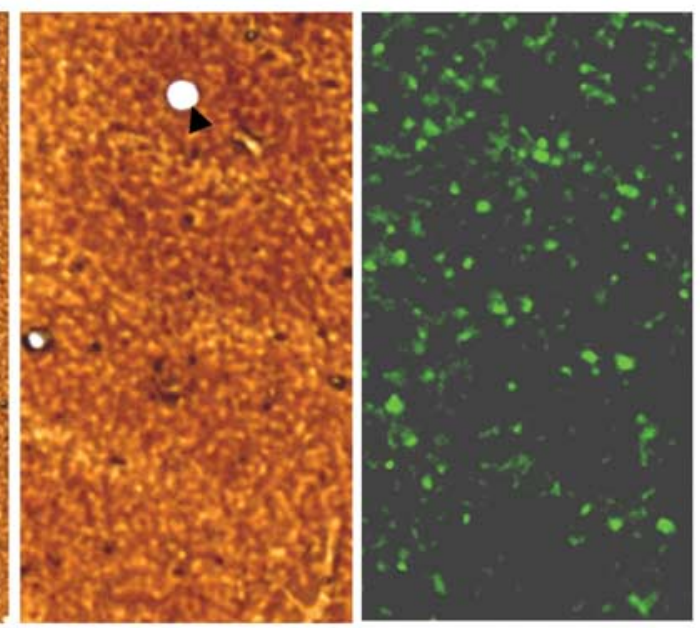

$100 \mu \mathrm{m}$

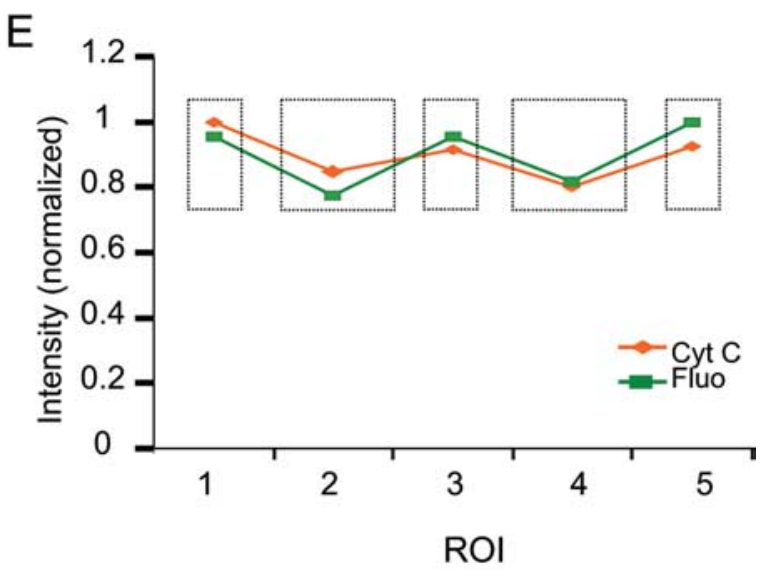

Figure 2. Projection pattern of dendritic bundles in layer 4 in barrel cortex. $\boldsymbol{A}$, Tangential section through layer 4 of barrel cortex showing cytochrome c-stained dark barrel hollows surrounded by the brighter barrel wall. Small ellipse (ROI 1) marks barrel wall. ( mark intensity in barrel wall. Large rectangles mark intensity in barrel hollow. High intensity corresponds to barrel wall and more labeled apical dendrites. Data are normalized to the ROI with the highest average intensity.

\section{Comparison of the dendrite overlap between cells in the same} cluster and in adjacent clusters

The possibility that bundling may generate an anatomical organization that is relevant for targeting thalamocortical input to the dendrites of clustered L5B pyramidal cells was also evaluated. Anatomically reconstructed pairs in the same or in adjacent clusters were scaled and superimposed to create "prototypic" bundles (Fig. 4). The apical dendrites from L5B pyramidal cells within a bundle are coextensive along the entire length of the dendrite (Fig. 4A). The anatomical separation between apical dendrites in adjacent bundles provides the possibility for axonal projections from the ventral posterior medial nucleus of the thalamus and layer $2 / 3$ pyramids to specifically target cells extending their apical dendrite within a single bundle (Fig. 4B). The difference in dendrite overlap between cells in the same and in adjacent cluster can be visualized by calculating (see Material and Methods) an 

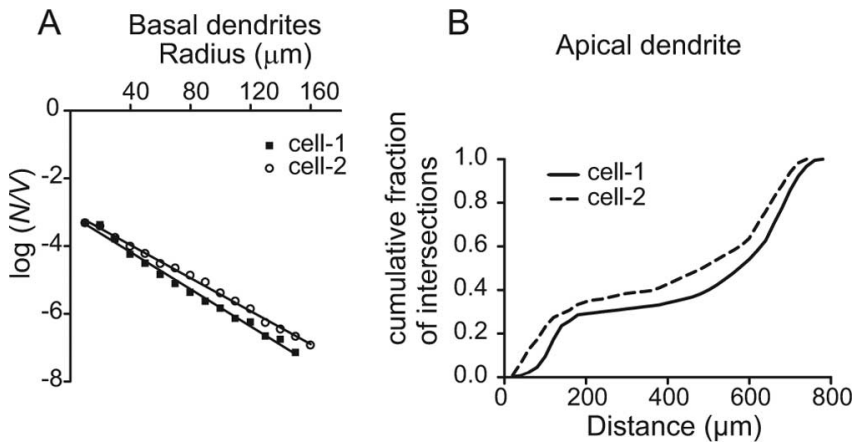

Figure 3. Comparison of the dendrite branching pattern. $\boldsymbol{A}$, The semilog Sholl method was used to compare the basal dendrite branching pattern. The graph shows the result for the cell pair depicted in Figure $6 . N$ is the number of intersections; $V$ is the volume of concentric spheres with radius $r$. The equation of the straight $\operatorname{line}[\log (N / V)=k \times r+m]$ is, for cell $1, \log (N / V)=$ $-0.0274 \times r-3.075\left(R^{2}=0.9918\right)$ and, for cell $2, \log (N / V)=-0.0242 \times r-3.006\left(R^{2}\right.$ $=0.9968)$. $\boldsymbol{B}$. The cumulative fraction of intersections, obtained from Sholl analysis, was used to compare apical dendrites. The graph shows data obtained from the cells in Figure 6 . The cumulative intersection distributions were not significantly different ( $p=0.102$; Kolmogorov-Smirnov two-sample test), indicating a similar branching pattern.

isosurface containing $80 \%$ of their dendrite overlap (Fig. $4 C, D$ ). We quantified these differences by calculating the percentage dendrite overlap for basal dendrites, oblique dendrites, and the apical tuft. The average dendrite overlap between cells in the same cluster was (1) for basal dendrites, $19 \pm 2 \%$ (mean \pm SD; $n=6$ pairs); (2) for oblique dendrites, $23 \pm 4 \%$; and (3) for the apical tuft, $21 \pm 2 \%$. Cells in adjacent clusters have similar dendrite overlap for (1) basal dendrites (18 $\pm 5 \% ; n=7$ pairs) and (2) oblique dendrites $(20 \pm 5 \%)$, but significantly less overlapping for (3) the apical tuft $(14 \pm 2 \%$; $p<0.05)$.

\section{Synaptic connectivity between layer 5 pyramidal neurons within and between clusters}

Having established that the L5B pyramidal neurons in the transgenic mice are organized in cell clusters with bundling of their apical dendrites, we next examined physiological properties of neurons in such cell clusters. It has been suggested that pyramidal neurons within a minicolumn are more densely interconnected, have larger EPSPs, and receive common inputs (Peters and Walsh, 1972; Peters and Yilmaz, 1993; Thomson and Deuchars, 1994; Mountcastle, 1997; Tanaka, 1998). Indeed, the definition of cells that are part of a minicolumn is that these cells share common response properties (Mountcastle, 2003). One such common property could be a near-synchronous action potential (AP) response pattern achieved by a higher connectivity within the minicolumn. We mapped connectivity between pyramidal cells in the same cluster or in adjacent clusters (including first-nearest and second-nearest cluster) using paired whole-cell recordings from fluorescent L5B pyramidal neurons. Fluorescent L5B pyramidal cells arranged in clusters were visualized in the green channel (Fig. 5A). The patch pipette was filled with a red fluorescent dye (Alexa 594) to mark the recorded cell and to confirm their apical dendrite projection (Fig. $5 B, C$ ). Figure $6 \mathrm{~A}$ shows a twophoton image of a living slice used for electrophysiological recordings. Connections between L5B pyramidal neurons were examined using an immobile patch-pipette recording from one cell and another, mobile search pipette, used to excite cells either in the same cluster or in adjacent clusters in the whole-cell or in the cell-attached recording configuration. Cells in Figure $6 \mathrm{~A}$ labeled with the same color symbol were classified as belonging to the same bundle based on the projection of their apical dendrite in a
A $\quad$ B

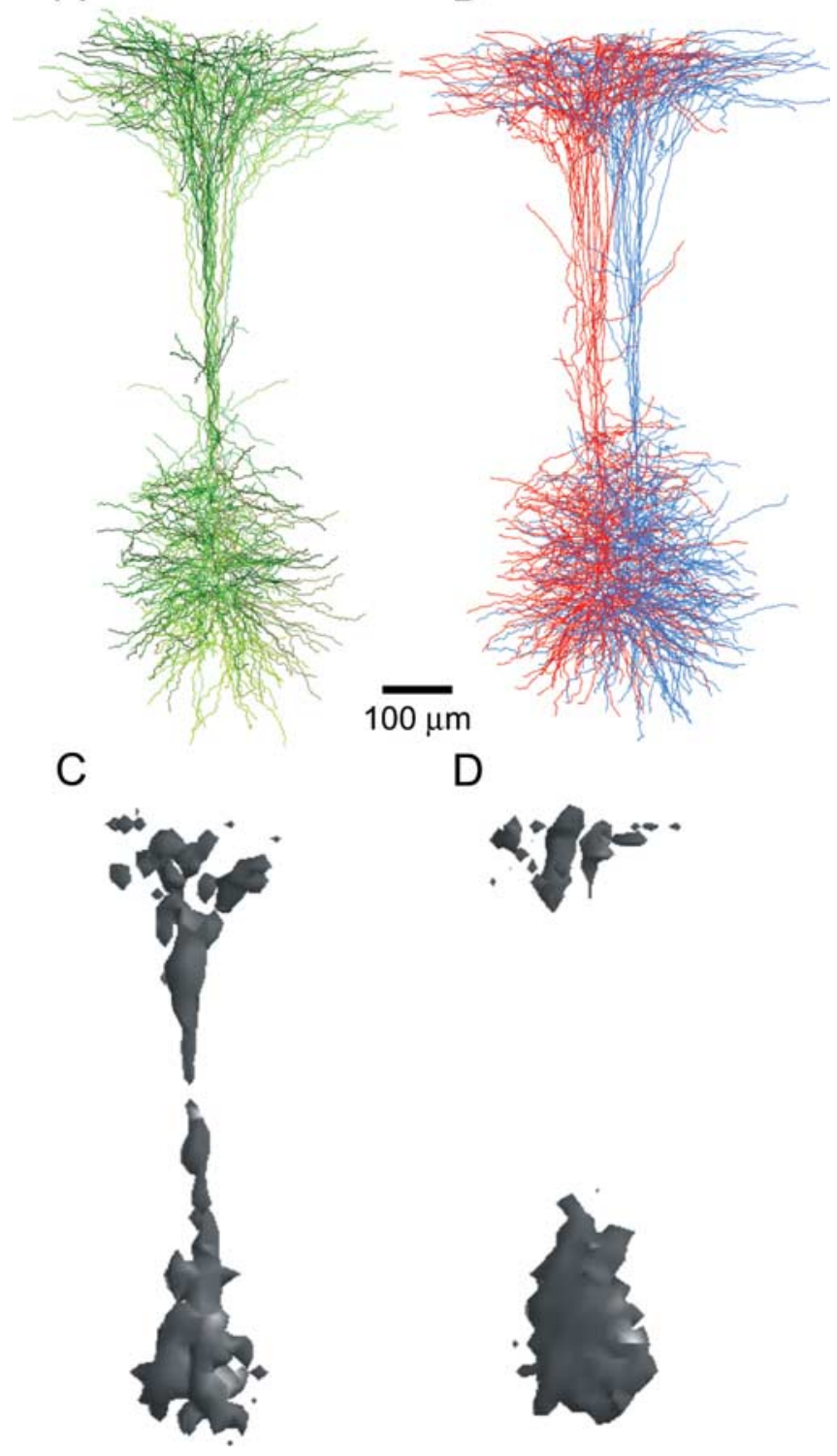

Figure 4. Overlap of dendrites within and between L5B pyramidal bundles. L5B pyramidal cells within the same cluster have a larger domain of overlapping dendrites. $A$, Reconstructions of four pairs (from 4 different experiments) in the same cluster were centered (in the $x$-direction) to the left cell in each pair, scaled, and superimposed. The relative distance in $x-, y$-, and $z$-directions is kept intact for each pair. Scale bar applies to all panels. $\boldsymbol{B}$, Reconstructions of five pairs (5 different experiments) in adjacent clusters were centered to the left cell in each pair, scaled, and superimposed. The relative distance in $x-, y$-, and $z$-directions is kept intact for each pair. Cells belonging to the same cluster have the same color (red or blue). C, The dendrite overlap between cells in a cluster (for the reconstructions in $A$ ) is shown in a $3 \mathrm{D}$ isosurface plot enclosing $80 \%$ of the overlapping dendrites. Cells within a cluster have overlapping basal and oblique dendrites, main apical trunk, and apical tuft. D, 3D isosurface plot for reconstructions in $\boldsymbol{B}$. Cells in adjacent clusters have overlapping basal and oblique dendrites and apical tuft, but well separated main apical trunks.

clearly confined bundle separated from adjacent bundles by 20-40 $\mu \mathrm{m}$. L5B pyramidal cell 1 and cell 2 were reciprocally connected (Fig. 6A,B) and were located in the same cluster, whereas none of the other neurons tested (triangles) were connected to cell 1 (connections to cell 2 not tested). Biocytin was included in the pipette, and the reciprocally connected neurons were reconstructed, showing that the apical dendrites remain in close proximity (Fig. $6 C$ ).

An example of a monosynaptic connection between L5B pyr- 
amids located in two different clusters is shown in Figure 7A. Evoking an AP in cell 2 elicited an EPSP in cell 1 (Fig. $7 B$ ). This pair of neurons was not reciprocally connected. When filled with biocytin and reconstructed, it is clear that the apical dendrites remain well separated until the bifurcation in layer 2 (Fig. 7C).

Figure $8 \mathrm{~A}$ shows a summary of all L5B pyramidal cell pairs recorded. The origin $[(0,0)$ coordinates $]$ of the graph marks the position of the postsynaptic cell, and the triangles mark the position of presynaptic neurons. Blue triangles indicate presynaptic neurons not connected, and red triangles mark the position of presynaptic neurons in monosynaptically connected pairs. Cell body position is plotted rather than the distance between apical dendrite bundles. For the L5B pyramidal cells recorded from, the median somata distance in the

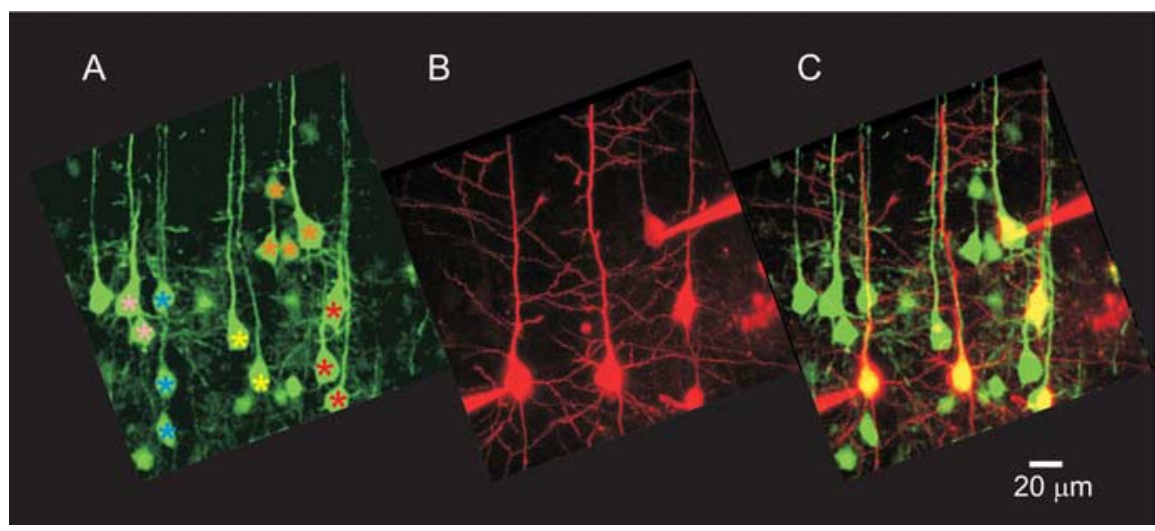

Figure 5. Cell clusters forming dendritic bundles. $A$, Two-photon image from a living slice showing L5B pyramidal cells arranged in cell clusters and with bundling apical dendrites. Cells labeled with the same color asterisks are in the same cluster. $\boldsymbol{B}$ Cells were filled through the patch pipette with a red fluorescent dye (Alexa Fluor 594) to mark the recorded cell and to confirm apical dendrite branching pattern. Two patch pipettes are shown recording from cells located in two different clusters. C, Images from $\boldsymbol{A}$ and $\boldsymbol{B}$ superimposed. Recordings were made from five different cells located in four different clusters (the 2 cells to the left are in the same cluster).

horizontal $x$-direction (parallel to pial sur-

face) between neurons in the same cluster was $8 \mu \mathrm{m}$ [range (absolute values), $0-28 \mu \mathrm{m}$ ], and for neurons in adjacent clusters (including first-nearest and second-nearest cluster), it was $33 \mu \mathrm{m}$ (range, 5-50 $\mu \mathrm{m}$ ). The median somata distance in the vertical $y$-direction (aligned to the bundle axis) was for cells in the same cluster $47 \mu \mathrm{m}$ and for cells in adjacent clusters $43 \mu \mathrm{m}$. Of 269 tested pairs, 25 pairs were connected (Figs. $8 A, 9 A$ ). For neurons in the same cluster, a synaptic connection was found in 17 of 158 pairs $(11 \%)$ (Figs. $8 B, 9 A$ ). Between neurons in adjacent clusters, synaptic connection was found in 7 of 73 pairs (10\%) (Figs. $8 C$, $9 A)$. L5B pyramidal neurons within the same cluster and in adjacent clusters are thus connected with equal probability ( $p=1$; Fisher's exact test). Connection probability was also analyzed grouping neurons according to distance between cell bodies, regardless of whether they were in the same cluster or not (Fig. 9B). This analysis showed that connectivity was independent of the distance $(0-50 \mu \mathrm{m})$ between cell somata $\left(p=0.67 ; \chi^{2}\right.$ test $)$ and suggests that synaptic connectivity is formed independently of dendritic bundling or somata distance (for the range $0-50 \mu \mathrm{m}$ ).

\section{Synaptic activity within and between bundles}

For L5B pyramidal neurons within the same cluster, the mean unitary EPSP amplitude (Fig. 9C) was $0.78 \pm 0.58 \mathrm{mV}$ (mean \pm $\mathrm{SD}$; median $=0.60$; range, $0.15-2.40 ; n=17)$, and for cells in adjacent clusters the mean unitary EPSP amplitude was $0.46 \pm$ $0.26 \mathrm{mV}$ (mean $\pm \mathrm{SD}$; median $=0.42$; range, $0.20-0.98 ; n=7$ ). Although the largest EPSPs were recorded from cells within the same cluster, the difference in EPSP amplitude was not significantly different ( $p=0.17$; unpaired $t$ test).

The larger dendrite overlap of the cells that are part of the same cluster (see Fig. 4) would imply that the cells in the same cluster could receive more common synaptic input than cells in adjacent clusters. Possible differences in the degree of common synaptic input were investigated using cross-correlation of membrane potential recordings of spontaneous subthreshold activity in control physiological solution or in the presence of a potassium channel blocker (4-AP; $10 \mu \mathrm{M})$ that increased synaptic activity. When necessary, negative current was injected to prevent the cell from spiking. The average cross-correlograms for cells in the same cluster ( $n=12$ pairs) had a peak at zero lag and a cross-correlation coefficient of 0.037 , and for cells in adjacent
A

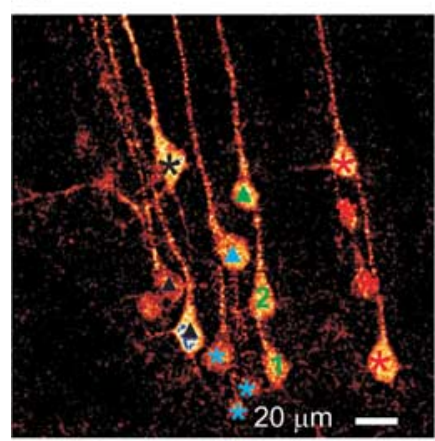

B

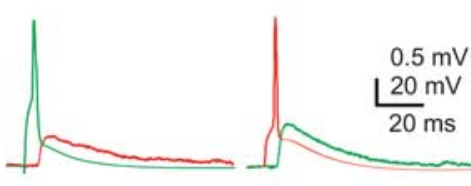

C

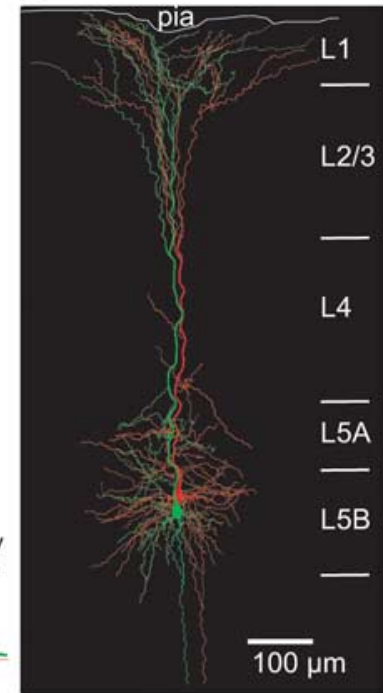

Figure 6. Connected pair of layer 5B pyramidal cells located in the same cluster. $\boldsymbol{A}$, Twophoton image from a living slice showing $L 5 B$ pyramidal cells with apical dendrites projecting in bundles toward the pial surface. Cells marked by the same color symbol (black, blue, green, and red) identify cells belonging to the same cluster. Triangles and numbers mark cells recorded from. A reciprocal connection existed between cell 1 and cell 2 . None of the other tested cells (triangles) were connected to cell 1 (connections to cell 2 not tested). $\boldsymbol{B}$, Eliciting an action potential in cell 1 (green) evoked an EPSP in cell 2 (red) and vice versa. Calibration: EPSP trace, $0.5 \mathrm{mV}, 20 \mathrm{~ms}$; AP trace, $20 \mathrm{mV}, 20 \mathrm{~ms}$. C, Reconstruction of connected L5B pyramidal cell 1 (green) and cell 2 (red).

clusters ( $n=8$ pairs) the cross-correlation coefficient was 0.034 at zero lag. Under the present conditions, we could thus not detect that cells within a cluster would receive significantly more common synaptic input $(p>0.05)$.

\section{Intrinsic membrane properties of L5B pyramidal neurons in} the same cluster

To further determine possible similarities of L5B pyramidal neurons in the same cluster, we analyzed the spiking pattern after current injection. In agreement with previous studies (Agmon 

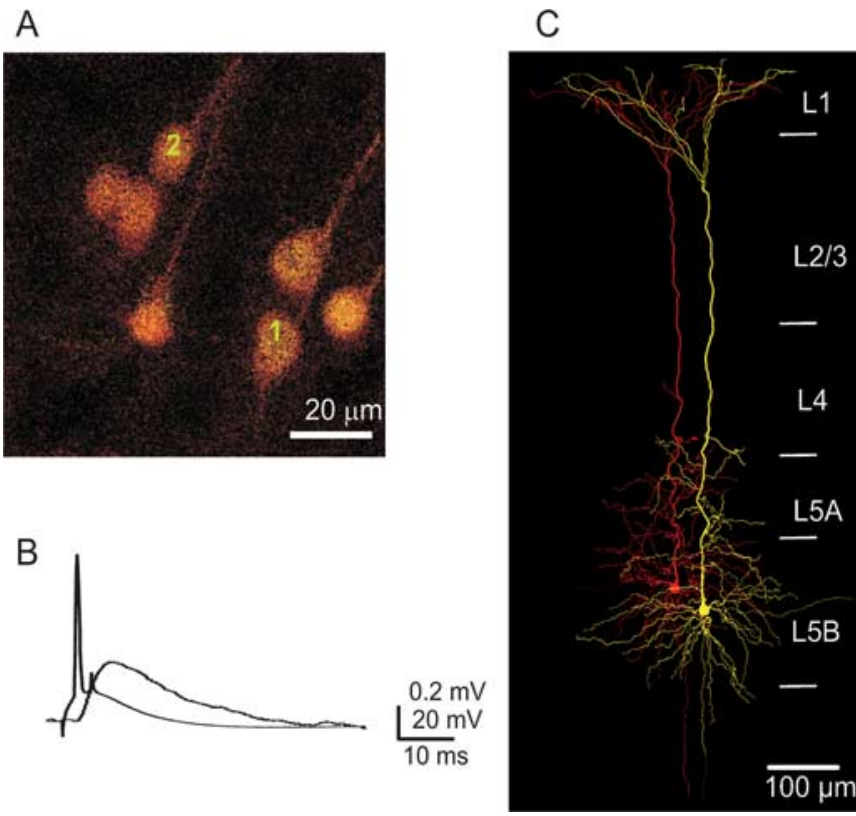

Figure 7. Connected pair of layer 5B pyramidal cells located in different clusters. $A$, Twophoton image of $L 5 B$ pyramidal cell clusters. The presynaptic (cell 2 ) and postsynaptic cell (cell 1) were in different clusters. $\boldsymbol{B}$, An action potential in cell 2 evoked a unitary EPSP in cell 1 . Cells were not reciprocally connected. Calibration: EPSP trace, $0.2 \mathrm{mV}, 10 \mathrm{~ms}$; AP trace, $20 \mathrm{mV}, 10 \mathrm{~ms}$. C, Reconstruction of connected L5B pyramidal cell 1 and cell 2.

and Connors, 1992; Williams and Stuart, 1999), cells were classified as either intrinsically bursting (IB-cells) or regular spiking (RS-cells). The spiking pattern was determined for two or three cells in the same cluster. In 11 of 25 clusters, the tested cells were classified as IB-cells, in 9 clusters both RS-cells and IB-cells were present, and in 5 clusters only RS-cells were found. Because not all cells in a cluster were tested, we conclude that not all L5B pyramidal cells in a cluster are of the same type.

\section{Discussion}

The bundles of apical dendrites characterized in the transgenic mice used in this study correspond anatomically to those previously described in mouse somatosensory cortex using fixed tissue (Escobar et al., 1986; White and Peters, 1993) because (1) the apical dendrites forming bundles originate from pyramidal neurons located in L5B, (2) the center-to-center distance between bundles was similar (20-40 $\mu \mathrm{m})$, and (3) in layer 4, the bundles were located predominantly in the wall of a cytoarchitectonic barrel.

\section{Common response properties}

If the minicolumn were a basic functional unit in the cortex in the sense that AP signaling in response to the same sensory stimulus could differ in two neighboring minicolumns, then this difference could, in principle, be based on more frequent and/or stronger connections between cells within a minicolumn. Because L5B pyramidal neurons are major output neurons of the neocortex (de Kock et al., 2007), one would expect that if they are part of a minicolumn and acting as a functional unit, then their spiking activity would be synchronized. This could strengthen the efficacy of the output to common target cells and could thus allow target cells to discriminate the signals emitted by neighboring minicolumns. We did, however, not find that L5B pyramidal neurons within a cluster are separated from the adjacent cluster because of increased connectivity, a large difference in synaptic strength, or more common synaptic input.

The connectivity ratio between L5B pyramidal cells reported here is similar to that previously reported for thick-tufted layer 5 pyramidal neurons in rat somatosensory cortex (Markram, 1997; Markram et al., 1997) and rat visual cortex (Song et al., 2005). In visual cortex, the number of three-neuron connection patterns was higher than that expected from a random network (Song et al., 2005). This implies that local circuits exist that are characterized by higher connectivity and synaptic strength. Our data suggest, however, that a single dendrite bundle is unlikely to be the underlying anatomical substrate for these functional circuits. The elements of a functional circuit could, however, be distributed over several bundles, with the functional unit not being a single minicolumn but a group of minicolumns bound together by common input (Mountcastle, 2003).

A possible function of dendritic bundling is not necessarily dependent on high connectivity between L5B pyramidal neurons within a cluster. Layer $2 / 3$ pyramidal neurons are organized around the central core of layer 5 apical dendrites, and stronger connections between layer $2 / 3$ pyramidal neurons and L5B pyramidal neurons may exist within the same cluster (Thomson and Bannister, 1998; Reyes and Sakmann, 1999). A common source of inhibition by Martinotti interneurons (Wang et al., 2004) with their characteristic axon projecting vertically, and thus well suited to be colocalized with bundled apical dendrites, may functionally separate different bundles.

\section{Common input}

The minicolumn hypothesis states that neurons in a minicolumn have a set of properties in common (Mountcastle, 2003). It is thus possible that neurons with bundling dendrites are not interconnected more frequently, but rather share other properties, such as inputs from common receptive fields in the case of sensory cortices. Under in vitro conditions, when cells are stimulated nonspecifically, we could not detect differences in common input for cells in the same or different cluster. Previous in vitro studies of rat neocortex have shown that correlation depends on the level of excitation (Silberberg et al., 2004) and layer stimulated and recorded from (Holmgren et al., 2003; Yoshimura et al., 2005). It is thus evident that correlation depends on the mode of stimulation, and it is possible that physiological stimuli would generate a stronger correlation between L5B pyramidal cells in the same cluster, with common synaptic input causing synchronized AP output activity.

To investigate the possible anatomical foundation for common synaptic inputs, we compared the dendrite branching pattern and the potential common innervation domains for cells located within the same cluster and for cells in adjacent clusters. We found that L5B pyramidal cells in the same cluster or in adjacent clusters had similar branching patterns. The branching pattern was, however, different between cells in different experiments (Figs. 6, 7, compare apical dendrite branching). The anatomical basis for barrel columns is the columnar geometry of thalamocortical projections (Jensen and Killackey, 1987; Gheorghita et al., 2006). Apical dendrites from L5B pyramidal cells in different bundles are well separated in layer 4 , where they could be targeted by thalamocortical afferents that are restricted to a single bundle (Fig. 4) (Favorov and Kelly, 1994). We found that, in addition to the separated main apical trunks, the dendrite overlap in the apical tuft is larger for cells within the same cluster ( $21 \%$ compared with $14 \%$ overlap). There is thus also an anatomical organization in the tufts in layer 1 that could preferentially 
A

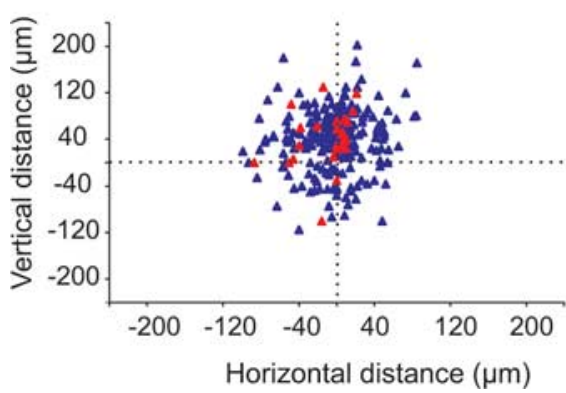

B

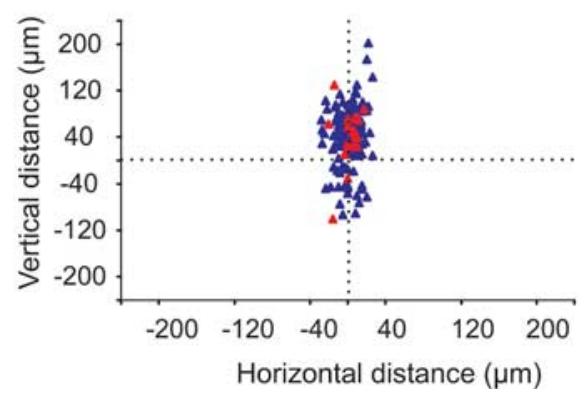

C

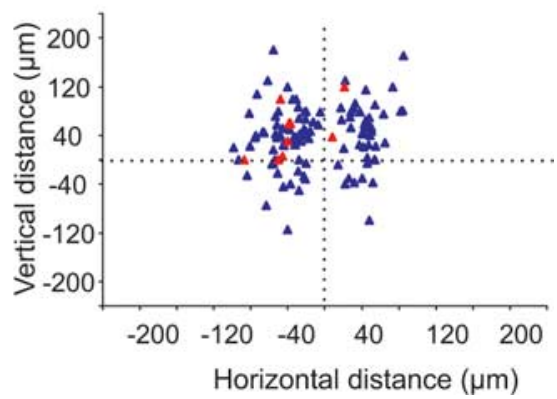

Figure 8. Layer $5 B$ pyramidal cell connectivity. $A$, Map of all tested connections. Distance was measured between cell bodies. Categorization of cells belonging to same or different cluster was made depending on the bundling of the apical dendrites. The postsynaptic cell is located at $(0,0)$ (marked by dotted lines). Blue triangles mark unconnected cells $(n=244)$, and red triangles mark connected cells $(n=25)$. B, Connectivity between cells in the same cluster. C, Connectivity between cells in neighboring clusters.

target input to single bundles. A single thalamocortical afferent, however, projects into the entire width of a column and does not appear to have a projection pattern that could be superimposed on individual bundles.

\section{Projection targets}

In the visual cortex, L5 pyramidal neurons that have different intrinsic membrane properties, apical dendrite branching pattern (tufted and nontufted), and position within L5 have been shown to project to different nuclei (Kasper et al., 1994; Christophe et al., 2005). In the frontal cortex, a similar difference in intrinsic membrane properties and apical dendrite branching exists between corticostriatal and corticopontine layer 5 pyramidal cells (Morishima and Kawaguchi, 2006). On the other hand, cells with apical dendrites that form bundles have been shown to project to the same target (Lev and White, 1997; Vercelli et al., 2004). We found differences in the spiking pattern after current injection for L5B pyramidal neurons that contribute to the same bundle, but all cells contributing to the bundle had similar apical dendrite branching characterized by a widespread tuft in layer 1 , were restricted to the lower part of layer 5 , at the level of corpus callosum had only an ipsilaterally projecting main axon, and in the majority of cases were retrogradely labeled by injections into pons (projection targets not injected with retrograde tracers can, however, not be excluded). The difference in spiking pattern could suggest different projection targets for cells in the same cluster. However, the similar morphological characteristics, laminar position, and retrograde labeling rather indicate that the pyramids that contribute to a cell cluster in L5B can have common target cells, although they have different spiking patterns. In rat barrel cortex, the pyramids in L5B can respond with short bursts of APs after a whisker deflection (de Kock et al., 2007). Thus, the difference in spiking patterns for cells located in the same cluster could indicate that after sensory stimulation, cells in the common target structures are activated with different efficacy.

\section{Conclusion}

The many unresolved questions regarding cortical columnar and minicolumnar organization have been discussed in a number of reviews (Roney et al., 1979; Jones, 2000; Mountcastle, 2003; Rockland and Ichinohe, 2004; Horton and Adams, 2005; Buxhoeveden and Casanova, 2005). The lack of evidence from in vitro recordings for a higher functional connectivity for L5B pyramidal cells organized as proposed core elements of minicolumns weakens the idea that minicolumns are formed by an underlying neuronal circuit that is restricted to the boundaries of anatomically defined substructures. Minicolumns could, however, consist of different arrangements of anatomical substructures such that physiologically defined minicolumns have a complex configuration that cannot be understood in terms of a repetitive canonical circuit characterized by higher connectivity within anatomical substructures. Indeed the existence of canonical circuits remains debatable (Nelson, 2002). If minicolumns contain different cell types, their existence can thus be combined with the idea that the underlying neuronal circuit is neither repetitive throughout cortex nor confined to the borders of a single anatomical substructure.

Even if a cell cluster is not part of a repeating circuit that fulfils the criteria postulated for minicolumns, the vertical bundles of apical dendrites formed by these clusters could serve other purposes. Dendrites within a bundle could be electrotonically coupled (Roney et al., 1979) such that back-propagating action potentials could influence other dendrites within the bundle. This could cause synaptic modifications (such as spike-timing- 
dependent plasticity) of inputs to clustered cells. The somatic membrane potential of the presynaptic cell can influence the release of neurotransmitter (Alle and Geiger, 2006; Shu et al., 2006). This effect depends on the (electrotonic) distance between the presynaptic cell soma and the synapse. Network activity modulating the membrane potential could thus have a larger influence on synaptic transmission between clustered cells if for clustered cells the synapses are (electrotonically) closer to the presynaptic cell soma.

The vertical migration of neurons along radial glia during development (Rakic, 1995a,b) also gives rise to a columnar arrangement of cells, without necessarily putting the same boundaries on the formation of functional microcircuits. The clue to understanding bundle formation might also be found in an interaction between surface proteins specific to bundled apical dendrites and molecules in the extracellular space that influence dendrite growth. There is thus the additional possibility that the vertical bundled alignment of L5B pyramidal cell dendrites reflects a developmental principle rather than a functional one.

\section{References}

Agmon A, Connors BW (1991) Thalamocortical responses of mouse somatosensory (barrel) cortex in vitro. Neuroscience 41:365-379.

Agmon A, Connors BW (1992) Correlation between intrinsic firing patterns and thalamocortical synaptic responses of neurons in mouse barrel cortex. J Neurosci 12:319-329.

Alle H, Geiger JRP (2006) Combined analog and action potential coding in hippocampal mossy fibers. Science 311:1290-1293.

Berglund K, Dunbar RL, Lee P, Feng G, Augustine GJ (2004) Imaging synaptic inhibition with Clomeleon, a genetically encoded chloride indicator. In: Imaging in neuroscience and development: a laboratory manual (Yuste R, Konnerth A, eds). New York: Cold Spring Harbor Laboratory.

Bruno RM, Khatri V, Land PW, Simons DJ (2003) Thalamocortical angular tuning domains within individual barrels of rat somatosensory cortex. J Neurosci 23:9565-9574.

Buxhoeveden D, Casanova MF (2005) Encephalization, minicolumns, and hominid evolution. In: Neocortical modularity and the cell minicolumn (Casanova MF, ed), pp 117-136. New York: Nova Science Publishers.

Buxhoeveden DP, Switala AE, Roy E, Casanova MF (2000) Quantitative analysis of cell columns in the cerebral cortex. J Neurosci Methods 97:7-17.

Catania KC (2002) Barrels, stripes and fingerprints in the brain-implications for theories of cortical organization. J Neurocytol 31:347-358.

Christophe E, Doerflinger N, Lavery DJ, Molnar Z, Charpak S, Audinat E (2005) Two populations of layer $V$ pyramidal cells of the mouse neocortex: development and sensitivity to anesthetics. J Neurophysiol 94:3357-3367.

DeFelipe J (2005) Reflections on the structure of the cortical minicolumn. In: Neocortical modularity and the cell minicolumn (Casanova MF, ed), pp 57-92. New York: Nova Science Publishers.

DeFelipe J, Hendry SHC, Hashikawa T, Molinari M, Jones EG (1990) A microcolumnar structure of monkey cerebral cortex revealed by immunocytochemical studies of double bouquet cell axons. Neuroscience 3:655-673.

de Kock CP, Bruno RM, Spors H, Sakmann B (2007) Layer and cell type specific suprathreshold stimulus representation in primary somatosensory cortex. J Physiol (Lond) 581:139-154.

Deschênes M, Bourassa J, Pinault D (1994) Corticothalamic projections from layer $\mathrm{V}$ cells in rat are collaterals of long-range corticofugal axons. Brain Res 664:215-219.

Duebel J, Haverkamp S, Schleich W, Feng G, Augustine GJ, Kuner T, Euler T (2006) Two-photon imaging reveals somatodendritic chloride gradient in retinal ON-type bipolar cells expressing the biosensor Clomeleon. Neuron 49:81-94.

Escobar MI, Pimienta H, Caviness Jr VS, Jacobson M, Crandall JE, Kosik KS (1986) Architecture of apical dendrites in the murine neocortex: dual apical dendritic systems. Neuroscience 17:975-989.

Favorov O, Whitsel BL (1988a) Spatial organization of the peripheral input to area 1 cell columns. I. The detection of 'segregates.' Brain Res 472:25-42.
Favorov O, Whitsel BL (1988b) Spatial organization of the peripheral input to area 1 cell columns. II. The forelimb representation achieved by a mosaic of segregates. Brain Res 472:43-56.

Favorov OV, Diamond ME (1990) Demonstration of discrete place-defined columns-segregates-in the cat SI. J Comp Neurol 298:97-112.

Favorov OV, Kelly DG (1994) Minicolumnar organization within somatosensory cortical segregates: I. Development of afferent connections. Cereb Cortex 4:408-427.

Feldmeyer D, Egger V, Lübke J, Sakmann B (1999) Reliable synaptic connections between pairs of excitatory layer 4 neurones within a single 'barrel' of developing rat somatosensory cortex. J Physiol (Lond) 521:169-190.

Feldmeyer D, Roth A, Sakmann B (2005) Monosynaptic connections between pairs of spiny stellate cells in layer 4 and pyramidal cells in layer $5 \mathrm{~A}$ indicate that lemniscal and paralemniscal afferent pathways converge in the infragranular somatosensory cortex. J Neurosci 25:3423-3431.

Fleischhauer K, Petsche H, Wittkowski W (1972) Vertical bundles of dendrites in the neocortex. Z Anat Entwicklungsgesch 136:213-223.

Georgopoulos AP, Merchant H, Naselaris T, Amirikian B (2006) Mapping of the preferred direction in the motor cortex. Proc Natl Acad Sci USA 26:11068-11072.

Gheorghita F, Kraftsik R, Dubois R, Welker E (2006) Structural basis for map formation in the thalamocortical pathway of the barrelless mouse. J Neurosci 26:10057-10067.

Helmchen F, Denk W (2005) Deep tissue two-photon microscopy. Nat Methods 12:932-940.

Holmgren C, Harkany T, Svennenfors B, Zilberter Y (2003) Pyramidal cell communication within local networks in layer $2 / 3$ of rat neocortex. J Physiol (Lond) 551:139-153.

Horton JC, Adams DL (2005) The cortical column: a structure without a function. Phil Trans R Soc B 360:837-862.

Hubel DH, Wiesel TN (1974) Sequence regularity and geometry of orientation columns in the monkey striate cortex. J Comp Neurol 158:267-293.

Hubel DH, Wiesel TN (1977) Ferrier lecture. Functional architecture of macaque monkey visual cortex. Proc R Soc Lond B Biol Sci 198:1-59.

Jensen KF, Killackey HP (1987) Terminal arbors of axons projecting to the somatosensory cortex of the adult rat. I. The normal morphology of specific thalamocortical afferents. J Neurosci 7:3529-3543.

Jones EG (2000) Microcolumns in the cerebral cortex. Proc Natl Acad Sci USA 97:5019-5021.

Kaas JH, Nelson RJ, Sur M, Merzenich MM (1981) Organization of somatosensory cortex in primates. In: The organization of the cerebral cortex (Schmitt FO, Worden FG, Adelman G, Dennis SG, eds), pp 237-261. Cambridge, MA: MIT.

Kasper EM, Larkman AU, Lübke J, Blakemore C (1994) Pyramidal neurons in layer 5 of the rat visual cortex. I. Correlation among cell morphology, intrinsic electrophysiological properties, and axon targets. J Comp Neurol 339:459-474.

Kohn A, Pinheiro A, Tommerdahl MA, Whitsel BL (1997) Optical imaging in vitro provides evidence for the minicolumnar nature of cortical response. NeuroReport 8:3513-3518.

Kuner T, Augustine GJ (2000) A genetically encoded ratiometric indicator for chloride: capturing chloride transients in cultured hippocampal neurons. Neuron 27:447-459.

Lev DL, White EL (1997) Organization of pyramidal cell apical dendrites and composition of dendritic clusters in the mouse: emphasis on primary motor cortex. Eur J Neurosci 9:280-290.

Lorente de Nó R (1938) Architectonics and structure of the cerebral cortex. In: Physiology of the nervous system (Fulton JF, ed), pp 291-330. New York: Oxford UP.

Lübke J, Egger V, Sakmann B, Feldmeyer D (2000) Columnar organization of dendrites and axons of single and synaptically coupled excitatory spiny neurons in layer 4 of the rat barrel cortex. J Neurosci 20:5300-5311.

Manns ID, Sakmann B, Brecht M (2004) Sub- and suprathreshold receptive field properties of pyramidal neurones in layers $5 \mathrm{~A}$ and $5 \mathrm{~B}$ of rat somatosensory barrel cortex. J Physiol (Lond) 556:601-622.

Markram H (1997) A network of tufted layer 5 pyramidal neurons. Cereb Cortex 7:523-533.

Markram H, Lübke J, Frotscher M, Roth A, Sakmann B (1997) Physiology and anatomy of synaptic connections between thick tufted pyramidal neurones in the developing rat neocortex. J Physiol (Lond) 500:409-440. McCasland JS, Woolsey TA (1988) High-resolution 2-deoxyglucose map- 
ping of functional cortical columns in mouse barrel cortex. J Comp Neurol 278:555-569.

Morishima M, Kawaguchi Y (2006) Recurrent connection patterns of corticostriatal pyramidal cells in frontal cortex. J Neurosci 26:4394-4405.

Mountcastle VB (1957) Modality and topographic properties of single neurons of cat's somatic sensory cortex. J Neurophysiol 20:408-434.

Mountcastle VB (1978) An organizing principle for cerebral function: the unit module and the distributed system. In: The mindful brain (Edelman GM, Mountcastle VB, eds), pp 7-50. Cambridge, MA: MIT.

Mountcastle VB (1997) The columnar organization of the neocortex. Brain 120:701-722.

Mountcastle VB (2003) Introduction: computation in cortical columns. Cereb Cortex 13:2-4.

Nelson S (2002) Cortical microcircuits: diverse or canonical? Neuron 36:19-27.

Panico J, Sterling P (1995) Retinal neurons and vessels are not fractal but space-filling. J Comp Neurol 361:479-490.

Peters A, Sethares C (1991) Organization of pyramidal neurons in area 17 of monkey visual cortex. J Comp Neurol 306:1-23.

Peters A, Sethares C (1996) Myelinated axons and the pyramidal cell modules in monkey primary visual cortex. J Comp Neurol 365:232-255.

Peters A, Walsh TM (1972) A study of the organization of apical dendrites in the somatic sensory cortex of the rat. J Comp Neurol 144:253-268.

Peters A, Yilmaz E (1993) Neuronal organization in area 17 of cat visual cortex. Cereb Cortex 3:49-68.

Purves D, Riddle DR, LaMantia AS (1992) Iterated patterns of brain circuitry (or how the cortex gets its spots). Trends Neurosci 10:362-368.

Rakic P (1995a) Radial glial cells: scaffolding for brain construction. In: Neuroglial cells. (Ketterman H, Ransom BR, eds), pp 746-762. New York: Oxford UP.

Rakic P (1995b) Radial versus tangential migration of neuronal clones in the developing cerebral cortex. Proc Natl Acad Sci USA 92:11323-11327.

Reyes A, Sakmann B (1999) Developmental switch in the short-term modification of unitary EPSPs evoked in layer 2/3 and layer 5 pyramidal neurons of rat neocortex. J Neurosci 19:3827-3835.

Rockland KS, Ichinohe N (2004) Some thoughts on cortical minicolumns. Exp Brain Res 158:265-277.

Roney KJ, Scheibel AB, Shaw GL (1979) Dendritic bundles: survey of anatomical experiments and physiological theories. Brain Res 1:225-271.

Schlaug G, Schleicher A, Zilles K (1995) Quantitative analysis of the columnar arrangement of neurons in the human cingulate cortex. J Comp Neurol 351:441-452.

Schmolke C, Künzle H (1997) On the presence of dendrite bundles in the cerebral cortex of the Madagascan lesser hedgehog tenrec and the redeared pond turtle. Anat Embryol (Berl) 196:195-213.
Schubert D, Staiger JF, Cho N, Kotter R, Zilles K, Luhmann HJ (2001) Layer-specific intracolumnar and transcolumnar functional connectivity of layer V pyramidal cells in rat barrel cortex. J Neurosci 21:3580-3592.

Shu Y, Hasenstaub A, Duque A, Yu Y, McCormick DA (2006) Modulation of intracortical synaptic potentials by presynaptic somatic membrane potential. Nature 441:761-765.

Silberberg G, Wu C, Markram H (2004) Synaptic dynamics control the timing of neuronal excitation in the activated neocortical microcircuit. J Physiol (Lond) 556:19-27.

Song S, Sjostrom PJ, Reigl M, Nelson S, Chklovskii DB (2005) Highly nonrandom features of synaptic connectivity in local cortical circuits. PLoS Biol 3:e68.

Swindale NV (1990) Is the cerebral cortex modular? Trends Neurosci 12:487-492.

Tanaka K (1998) Columnar organization in the inferotemporal cortex. In: Extrastriate cortex in primates (Rockland KS, Kaas JH, Peters A, eds), pp 469-495. Dordrecht, Netherlands: Kluwer Academic.

Thomson AM, Bannister AP (1998) Postsynaptic pyramidal target selection by descending layer III pyramidal axons: dual intracellular recordings and biocytin filling in slices of rat neocortex. Neuroscience 84:669-683.

Thomson AM, Deuchars J (1994) Temporal and spatial properties of local circuits in neocortex. Trends Neurosci 17:119-126.

Tommerdahl M, Favorov O, Whitsel BL, Nakhle B, Gonchar YA (1993) Minicolumnar activation patterns in cat and monkey SI cortex. Cereb Cortex 3:399-411.

Vercelli AE, Garbossa D, Curtetti R, Innocenti GM (2004) Somatodendritic minicolumns of output neurons in the rat visual cortex. Eur J Neurosci 20:495-502.

Wang Y, Toledo-Rodriguez M, Gupta A, Wu C, Silberberg G, Luo J, Markram H (2004) Anatomical, physiological and molecular properties of Martinotti cells in the somatosensory cortex of the juvenile rat. J Physiol (Lond) 561 1:65-90.

Waters J, Larkum M, Sakmann B, Helmchen F (2003) Supralinear $\mathrm{Ca}^{2+}$ influx into dendritic tufts of layer $2 / 3$ neocortical pyramidal neurons in vitro and in vivo. J Neurosci 23:8558-8567.

White EL, Peters A (1993) Cortical modules in the posteromedial barrel subfield (Sml) of the mouse. J Comp Neurol 334:86-96.

Williams SR, Stuart GJ (1999) Mechanisms and consequences of action potential burst firing in rat neocortical pyramidal neurons. J Physiol (Lond) 521:467-482.

Wimmer VC, Nevian T, Kuner T (2004) Targeted in vivo expression of proteins in the calyx of Held. Pflugers Arch 449:319-333.

Yoshimura Y, Dantzker JL, Callaway EM (2005) Excitatory cortical neurons form fine-scale functional networks. Nature 433:868-873. 